\title{
DCPs in the
}
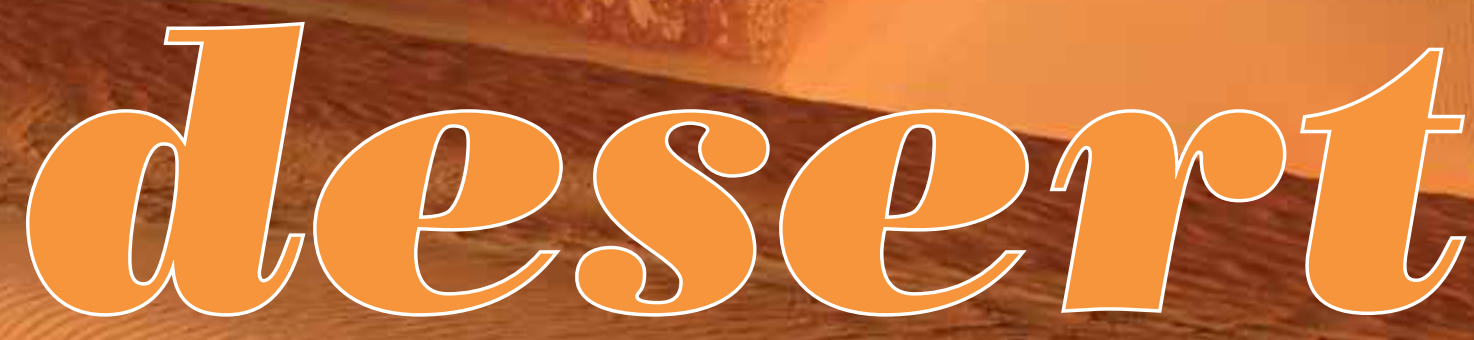

\section{Colleagues Sue Field ${ }^{*}$} and Amanda Feest were invited to train DCPs working in sunny Abu Dhabi. In this diary of their experience, Sue describes their second exciting visit.

* Dental Nurse Tutor, Haywards Heath Training Centre for Dental Care Professionals, NHS West Sussex

\section{IIuesday 9 November 2010 $4.30 \mathrm{am}$}

It's a wet, windy and very dark November morning. My colleague Amanda Feest and I are on the M25 heading for Heathrow Airport on the first leg of our journey to Abu Dhabi in the United Arab Emirates (UAE).

We have been fortunate enough to be invited back for a second time to deliver CPD training to dental care professionals (DCPs) attending 'Dentistry 2010', the UAE's International Dental Conference.

We were invited in 2009 and again this year by Professor Asmat Lone, the Middle East's coordinator for Postgraduate Dental and Medical Education at the University of London, University of Cologne (Germany) and the Texas Health Science Centre, San Antonio (USA).

Professor Lone had read an article published in the GDC Gazette about the training centre for DCPs that Amanda and I had set up in Haywards Heath in West Sussex. On the strength of that he asked us to provide some training for DCPs working in the Emirates.

We were delighted to oblige and despite a certain amount of trepidation, thoroughly enjoyed our first trip. We were made to feel very welcome and the DCPs that we trained seemed thirsty for knowledge.
'I awake to glorious

sunshine and views

of the sea in the

distance from my

bedroom window.'

\subsection{0pm (UAE time)}

Seven and a half hours and 3,000 miles later we touch down at Abu Dhabi International Airport. The doors to the terminal building slide open and we are enveloped by the sticky night time heat. The scarves and coats of this morning are discarded and the cold wet start to our day is forgotten.

After a short taxi ride past beautifully illuminated mosques and minarets we arrive at our hotel, which adjoins the Abu Dhabi National Exhibition Centre (ADNEC) where the conference is taking place. ADNEC is the largest conference and exhibition venue in the Middle East.

We're both tired after the long journey so after some food and a refreshing shower, it's off to bed. 


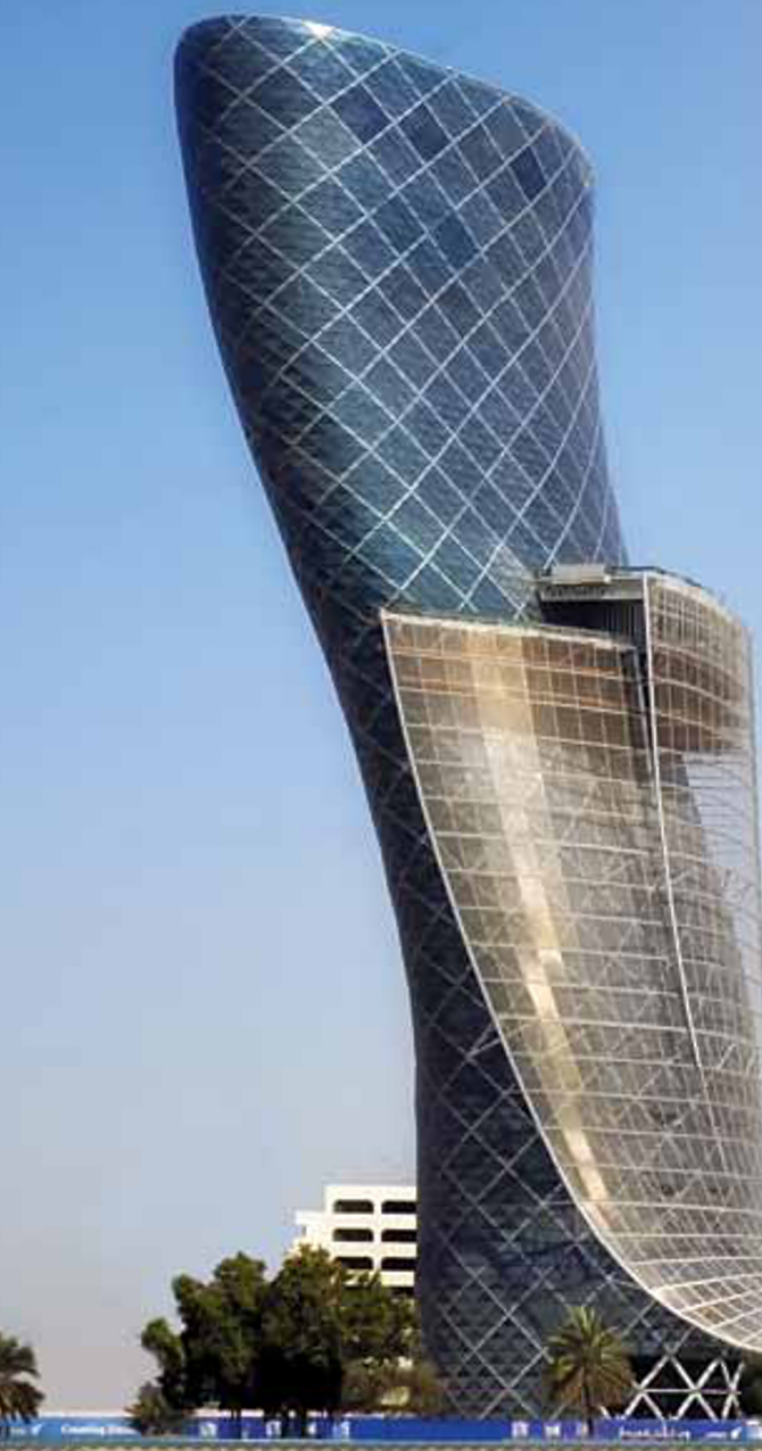

II

day themselves, which makes us even more

$$
\text { determined to make it worth their while.' }
$$

\section{Wednesday 10 November}

\section{$7.45 \mathrm{am}$}

I awake to glorious sunshine and views of the sea in the distance from my bedroom window.

We have the day to ourselves today. Our first port of call is the Exhibition Centre. We are welcomed like old friends by Professor Lone and the team of co-ordinators before being shown the vast room where we will be delivering the training.

We had been led to believe that there would be around 50 DCPs attending the workshops tomorrow. We are therefore stunned to learn that numbers have now risen to around 80 delegates.

To keep the butterflies at bay we take a trip to the shopping mall and order lunch in a fantastic revolving restaurant with panoramic views over Abu Dhabi.

Having eaten far too much, we use the afternoon to sit by the pool and go over our lecture notes one more time. Followed by even more food and another early night!

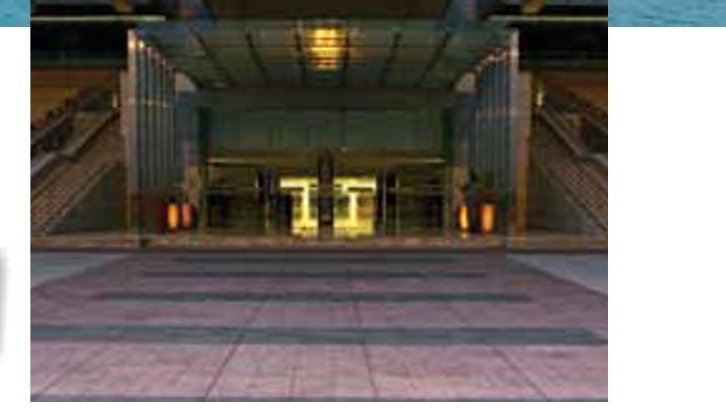

\section{Thursday 11 November}

\section{$8.00 \mathrm{am}$}

Laden with bags of resources, we take the short walk to the Exhibition Centre. It's only just $8 \mathrm{am}$ but already the temperature outside is around $80^{\circ} \mathrm{F}$. Sadly, that's the last we'll see of the sunshine. Our day begins at 9.30am with the first presentation and ends at $6.30 \mathrm{pm}$, by which time it will be dark. 


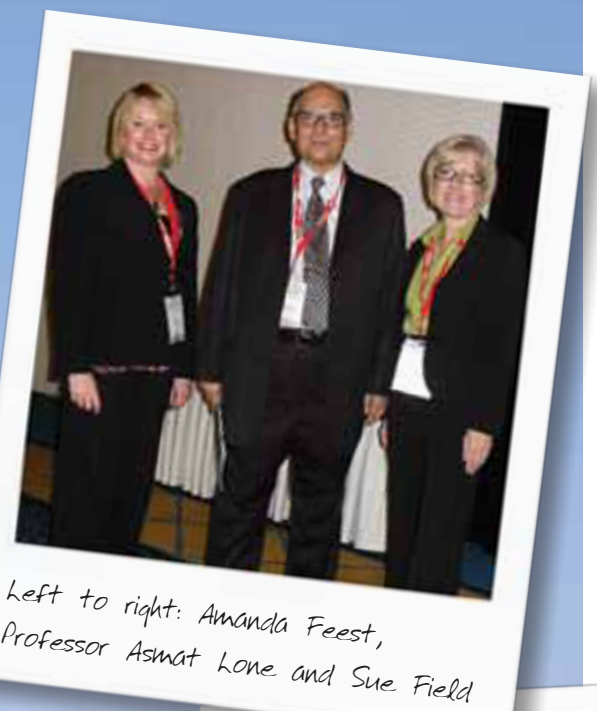

professional development (CPD), and how to create a personal development plan (PDP).

We know from our contacts in the Emirates that as a profession, dental nursing out here is a little way behind the UK but they are striving to catch us up.

We follow the lecture by taking it in turns to deliver workshop presentations throughout the rest of the day on Infection Control, Medical Emergencies, Radiation Protection, Communication Skills and Oral Health Education. We were concerned that our usual interactive style of presenting might prove difficult with such a large group, but we had the use of a hand held microphone and everybody was considerate in allowing others to be heard when necessary.

We end the day with a quiz which is noisy, competitive, and fun. The winning table receive sticks of Brighton rock which they seem very pleased with.

We give out evaluation forms for the delegates to complete and exchange these for certificates of attendance to make the training verifiable.

Amanda and I are exhausted and hoarse, but absolutely delighted with the way that the day has gone.

We begin the process of packing up and say our goodbyes to the team, who wish us a safe journey home and hope to see us again next year.

\subsection{0pm}

Once back at the hotel we unwind in the warm evening breeze of the rooftop bar with a very welcome glass of wine and review the evaluation forms that the delegates completed. They are all very positive and include some lovely comments: 'Thanks ... you made it nonboring!'; 'We had so much fun'; 'Presenters are fabulous and topics exciting.' The warm glow we are both experiencing has nothing to do with the wine!

\section{$11.00 \mathrm{pm}$}

We are in the taxi heading for Abu Dhabi International Airport for our 2.35am (!!) flight back to Heathrow. To keep ourselves awake we wander around the duty free outlets and do a bit of Christmas shopping. Once on the plane thankfully, we sleep.

\section{Friday 12 November \\ 6.45am Heathrow Airport}

The doors to the terminal building slide open and... it's absolutely freezing!
I begin the first lecture 'The Rise of the Dental Nurse' which explains UK statutory registration, the importance of continuing
'The warm glow we are

both experiencing

has nothing to do

with the wine!'

\section{HAYWARDS HEATH IRAINING CENTRE FOR DCPS}

Amanda and Sue opened the Haywards Heath Training Centre for Dental Care Professionals in September 2007 and have been expanding ever since.

The Centre currently runs the following courses:

- A Foundation Course for Denta Nurses - designed for dental nurses with less than six months' chairside experience

- The NEBDN National Certificate in Dental Nursing

- The NEBDN post certificate course in Oral Health Education

\section{CPD updates in:}

- Infection Control

- Radiation Protection

- Law, Ethics and Professionalism

- Communication Skills

- Child Protection

- COSHH \& Risk assessment

- Communication Skills and Ethics for Practice Managers

From March 2011 the Centre will be introducing updates in:

- Medical Emergencies

- Understanding the requirements of $\mathrm{CQC}$

- Infection Control for Practice Managers. 